\author{
استفاده از نانوجاذب برى راش اصلاح شده در حذف نيترات از محلولهاى آبى \\ در سيستم پيوسته \\ طيبه دهقان'، محمدعلى غلامى سفيد كوهى'، مجتبى خوشروش' و نر گس صمدانى لنخرودى '

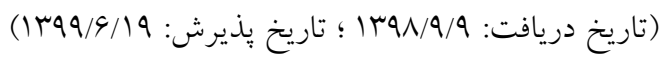

جكيده

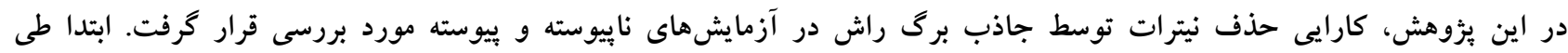

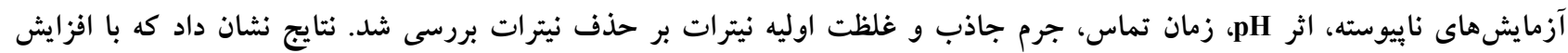

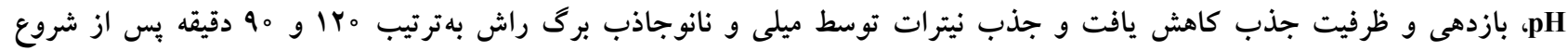

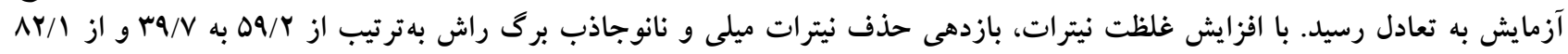

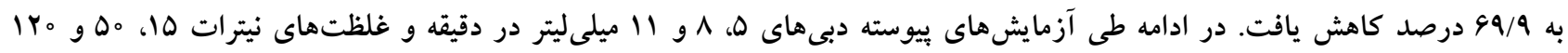

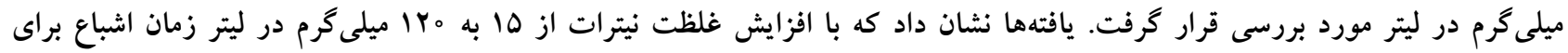

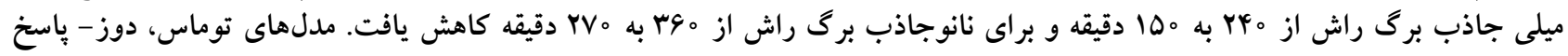

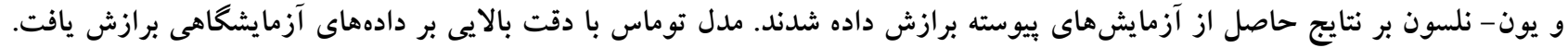

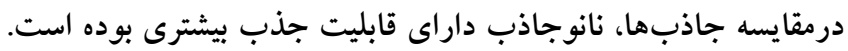

وازههاى كليدى: آزمايش ناييوسته، برى راش، ستون بستر -ثابت، نانوجاذب

1. كروه مهندسى آب، دانشخاه علوم كثاورزى و منابع طبيعى سارى، ايران

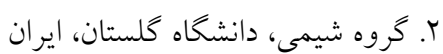

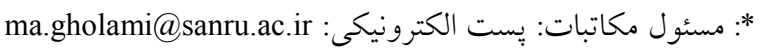


در آزمايش هاى بيوسته با بستر ثابت مورد مطالعه قرار كرفـت.

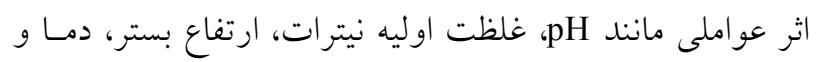

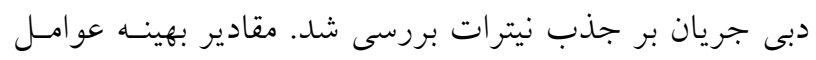

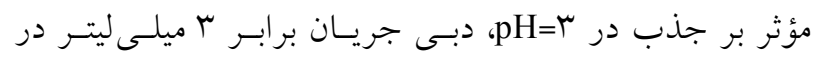

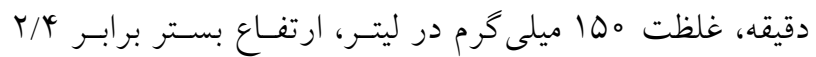

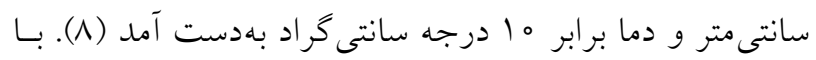

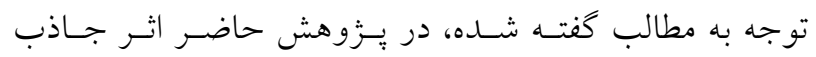

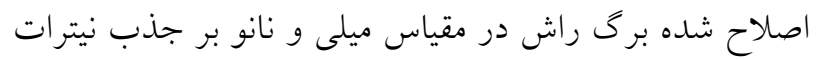

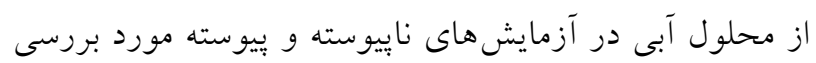

$$
\text { قرار گرفت. }
$$

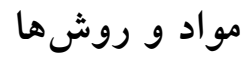

در اين يزّوهش برى درخت راش بهعنوان جاذب مورد استفاده

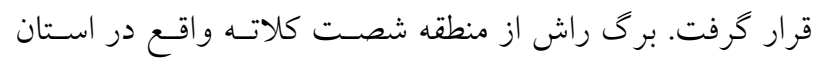

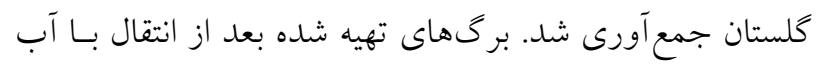

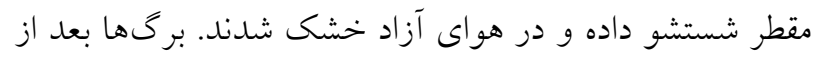

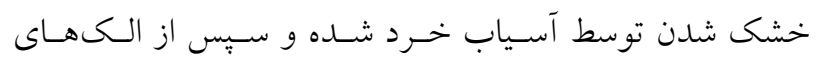

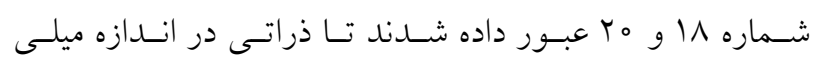

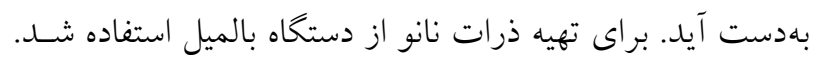

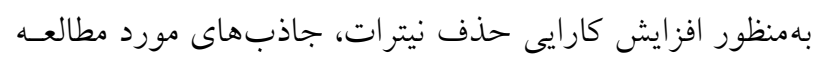

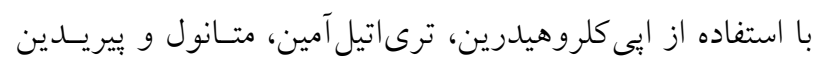

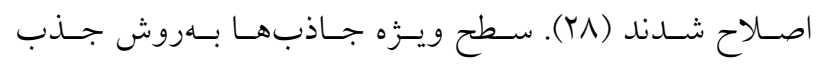
متيلنبلو تعيين شد. در اين روش ابتدا غلظتهاى ا، هـ، م 1، 10

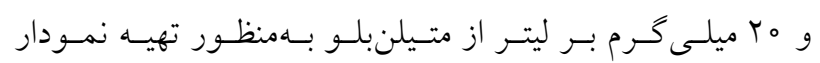

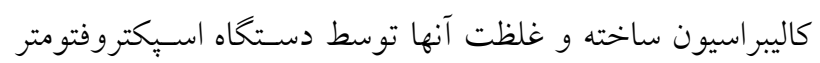

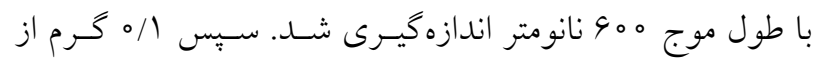

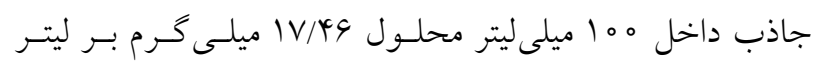

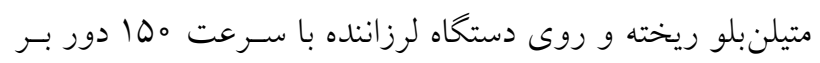

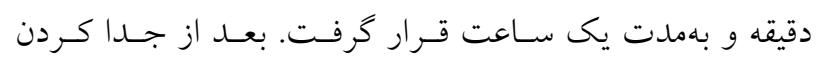

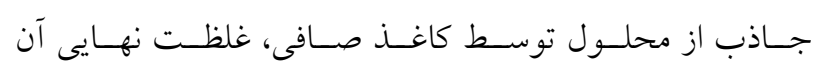

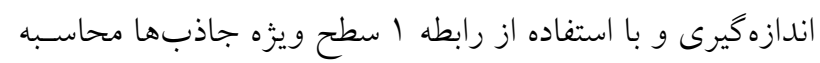

شد (10).

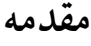

نيتروزن براى رشد و توسعه كياهان ضرورى اسـت. كشـاورزان

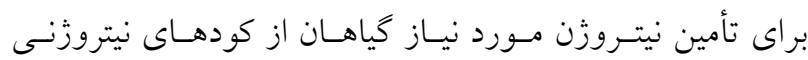

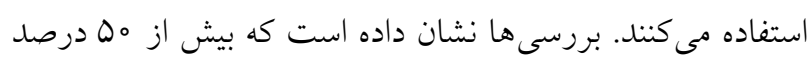

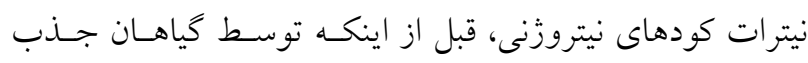

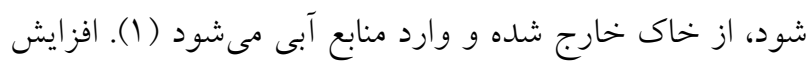

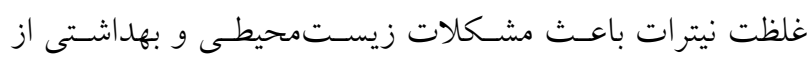

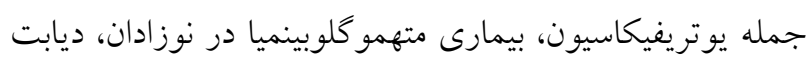

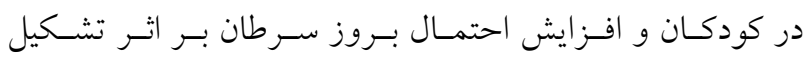

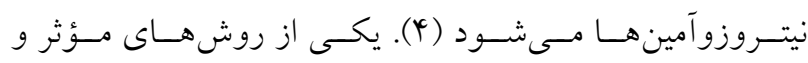

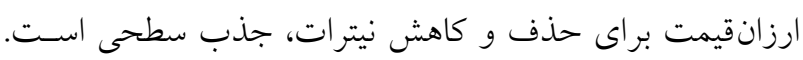

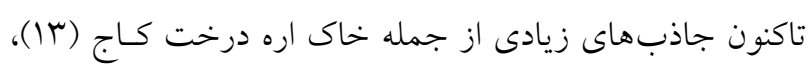

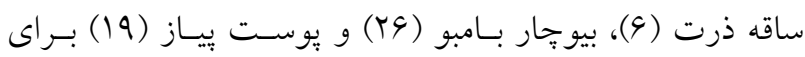
حذف و كاهش نيترات بهكار برده شدهاند. امروزه فناورى نـانو،

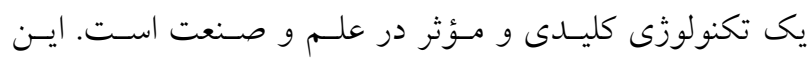

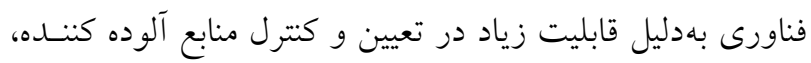

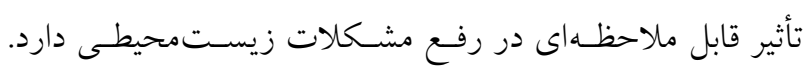

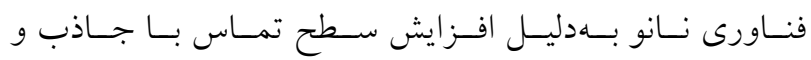

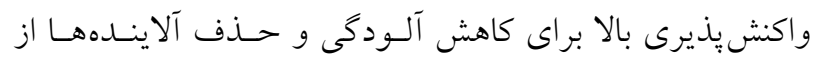

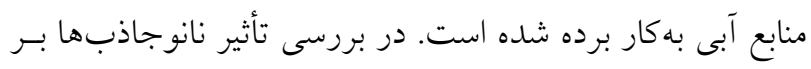

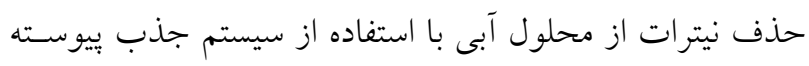

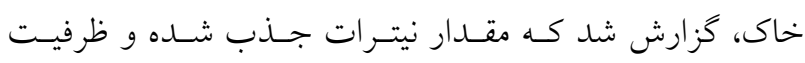

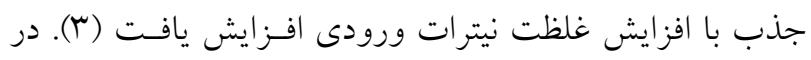

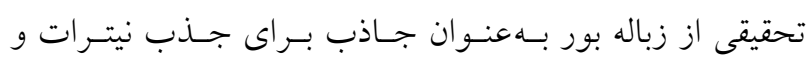

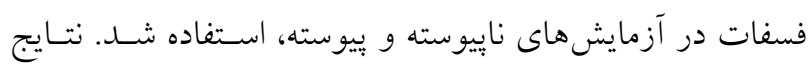

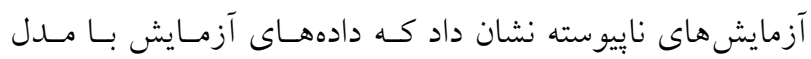

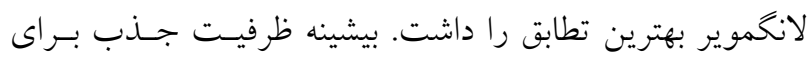

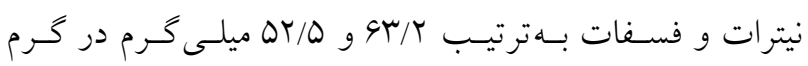

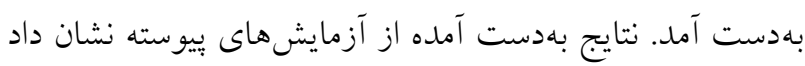

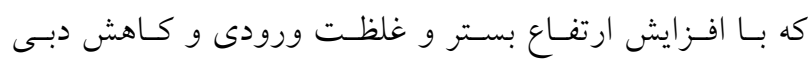

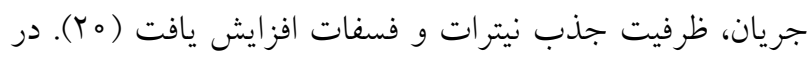

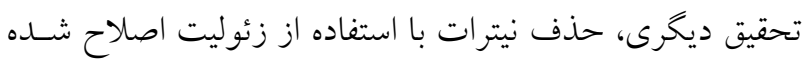


انتخابى مشخص مىشود كه سطح جاذب همخن يـا غيـرهمخن

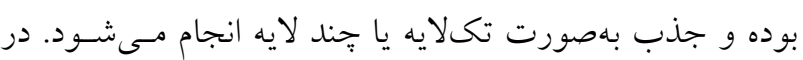

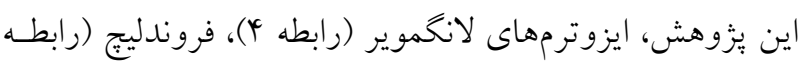

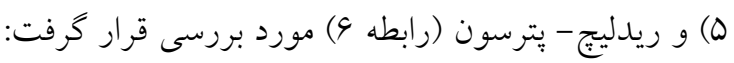
$\mathrm{q}_{\mathrm{e}}=\frac{\mathrm{bq}_{\mathrm{m}} \mathrm{C}_{\mathrm{e}}}{1+\mathrm{bC}_{\mathrm{e}}}$

$\mathrm{q}_{\mathrm{e}}=\mathrm{k}_{\mathrm{F}} C_{\mathrm{e}}^{1 / \mathrm{n}_{\mathrm{F}}}$

$\mathrm{q}_{\mathrm{e}}=\frac{\mathrm{aC}_{\mathrm{e}}}{1+\mathrm{bC}_{\mathrm{e}}^{\mathrm{n}}}$

در روابط بالا، qu، ظرفيت جذب در حالت تعـادل (mg/g)؛ غلظت ماده جذب شونده در حالت تعادل (mg/L)؛ ظرفيـت جـذب جـاذب (mg/g)؛ b، ثابـت ايزوتــرم لانخمـوير

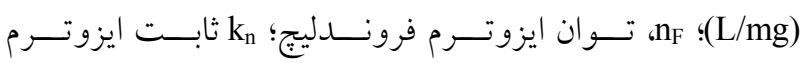
فروندليج؛

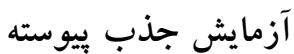

بهمنظور بررسى فرايند جذب در آزمايشهاى ييوسته از ستون با

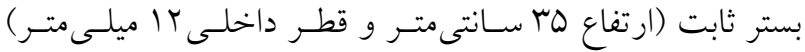
استفاده شد. در ابتدا و انتهاى ستون، از يشم شيشه اسـتفاده شـــ

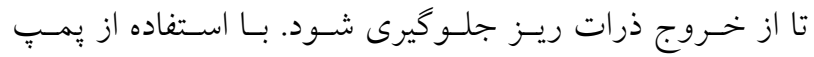

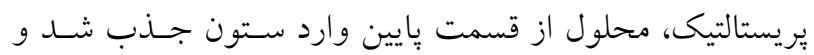

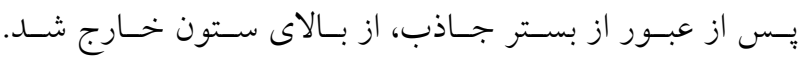
نمونهبردارى از خروجى ستون در مدت زمانهاى مختلف انجام

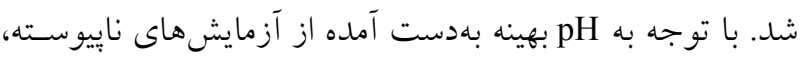

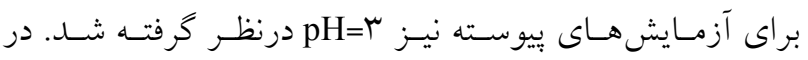

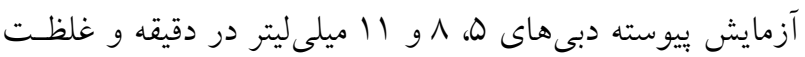

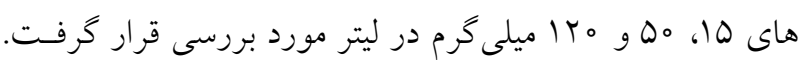

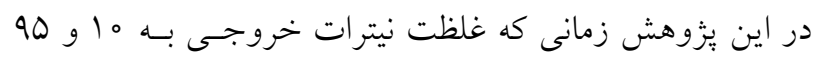
درصد غلظت اوليه رسيد، بهترتيب زمـان رخنـه و زمـان اشـباع

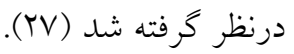

مدلهاى جذب ييوسته طراحى موفق فرايند جذب در بستر ثابـت يـك سـتون نيـاز بـهـ
$\mathrm{S}_{\mathrm{g}}=\mathrm{b} \frac{\mathrm{N}_{\mathrm{A}}}{\mathrm{M}_{\mathrm{MB}}} \delta_{\mathrm{MB}}$

كه در آن: b، تعداد مولكولهاى جذب شده متيلنبلو به جـاذب برحسب ميلى گرم در ميلى گرم؟ Nم، عدد آوو گادرو كه برابـر بـا

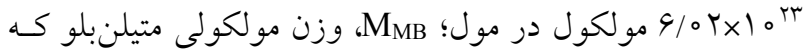

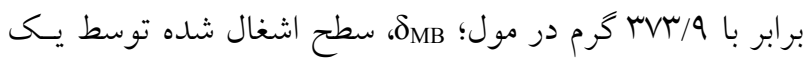

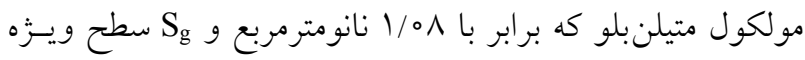

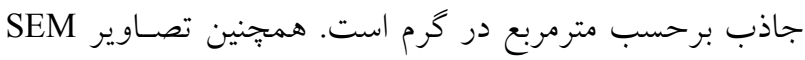

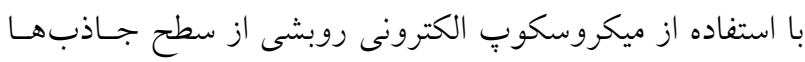
قبل و بعد از اصلاح تهيه شد. آزمايش هاى جذب ناييوسته

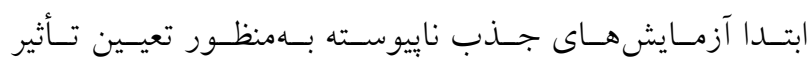
يارامترهاى مختلف بر فرايند جذب با استفاده از جـاذب بـرى راش در دو مقياس ميلى و نانو تحت شرايط: pH (r-1 )، زمان

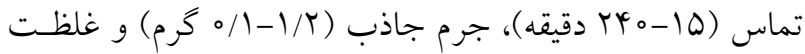

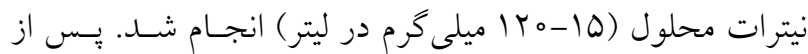
كذشــت زمـان مـورد نظـر، غلظـت نمونسههـا توسط دستخاه

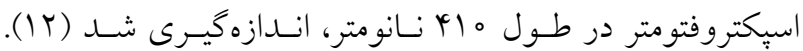
درصد بازدهى جـــب و ميـزان جـــب نيتـرات از روابـط زيـر

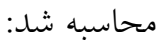

$\% \mathrm{R}=\frac{\mathrm{C}_{0}-\mathrm{C}_{\mathrm{f}}}{\mathrm{C}_{0}} \times 100$

$\mathrm{q}=\frac{\mathrm{C}_{0}-\mathrm{C}_{\mathrm{f}}}{\mathrm{m}} \times \mathrm{V}$

كه در آن: q، ميزان جذب ماده حل شده در واحد جـرم جـاذب (ظرفيت جذب) (mg/g)؛ (m)، غلظـت اوليـه مـاده حـل شـونده (mg/L) كذشت زمان تعادل؛ m، مقدار جاذب (mg) و V حجم محلـول

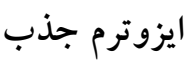
بهمنظور بررسى فراينـا جـــب بـين جـاذب و جـذب شـونده،

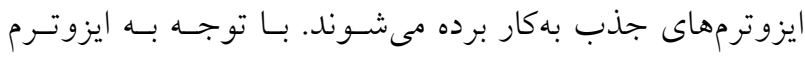



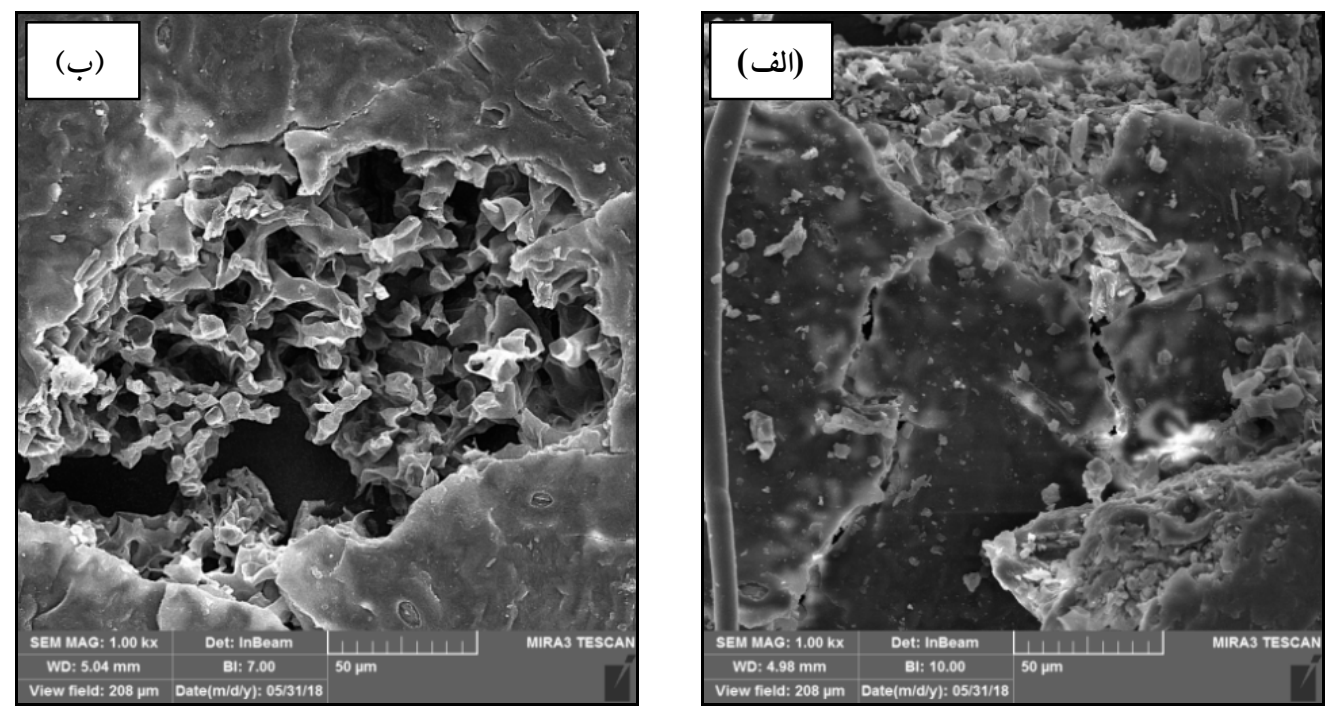

شكل 1. تصاوير SEM ميلىجاذب برى راش: الف) قبل از اصلاح و ب) بعد از اصلاح

سطح جاذب بِ از اصلاح داراى خلل و فرج بيشتر و عميقتر شده كه نشاندهنده قابليت جذب بهتر نيترات است.

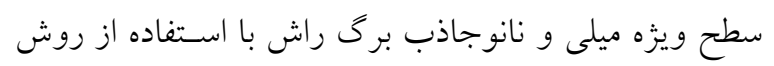

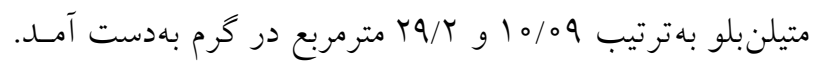

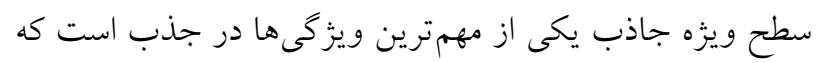

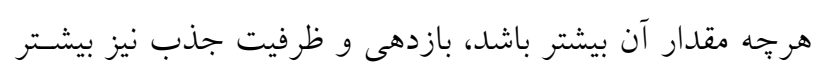

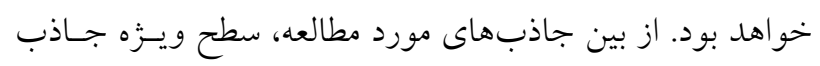

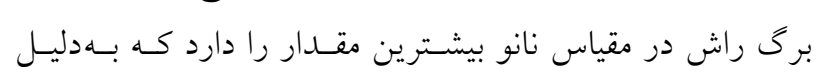

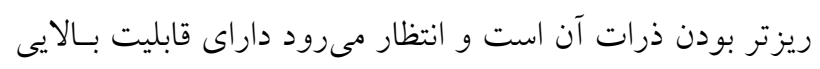

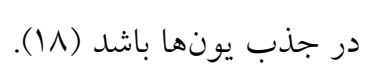

$$
\text { نتايج آزمايشهاى ناييوسته }
$$

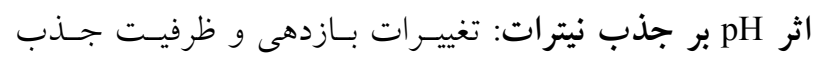

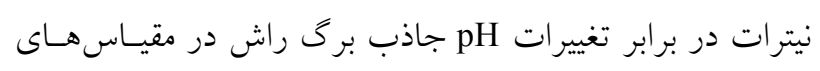

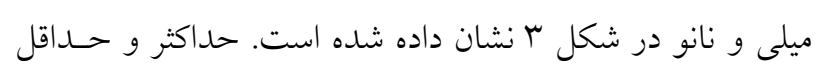

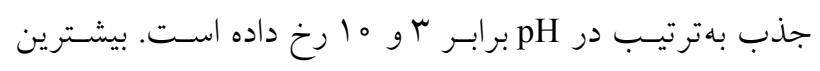

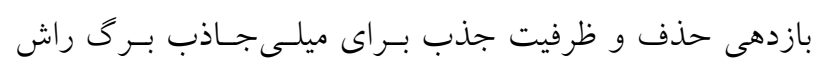

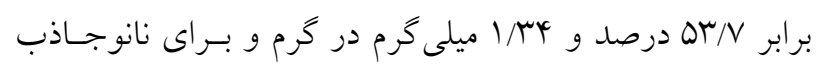

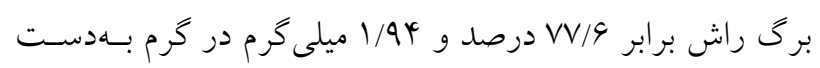

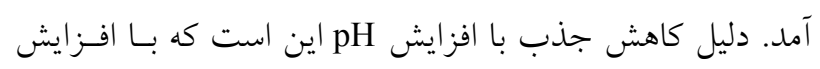

يشي بينى مناسب منحنى غلظت- زمان يا همان منحنى رخنه بـراى

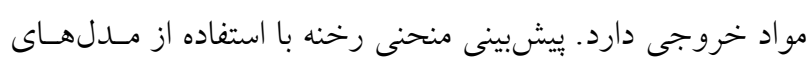

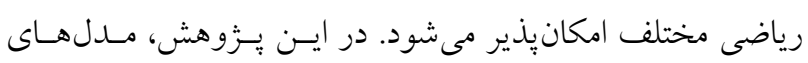

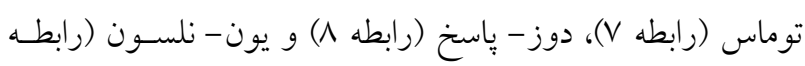

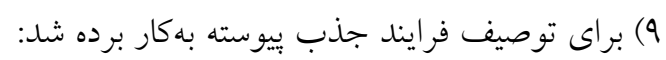
$\mathrm{LN}\left(\frac{\mathrm{C}_{0}}{\mathrm{C}_{\mathrm{t}}}-1\right)=\frac{\mathrm{K}_{\mathrm{Th}} \mathrm{qm}}{\mathrm{Q}}-\mathrm{K}_{\mathrm{Th}} \mathrm{C}_{0} \mathrm{t}$ $\frac{\mathrm{C}_{\mathrm{t}}}{\mathrm{C}_{\mathrm{O}}}=1-\frac{1}{1+\left(\frac{\mathrm{QC}_{0} \mathrm{t}}{\mathrm{q}_{\mathrm{DR}} \mathrm{m}}\right)^{\mathrm{a}}}$

$\mathrm{LN} \frac{\mathrm{C}_{\mathrm{t}}}{\mathrm{C}_{0}-\mathrm{C}_{\mathrm{t}}}=\mathrm{k}_{\mathrm{YN}} \mathrm{t}-\tau \mathrm{k}_{\mathrm{YN}}$

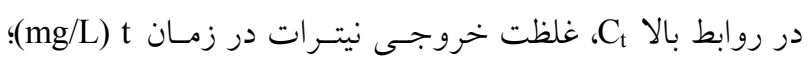

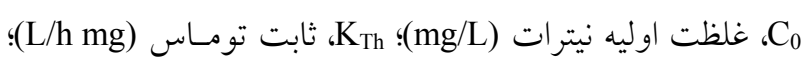

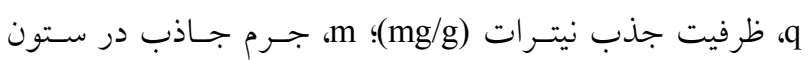

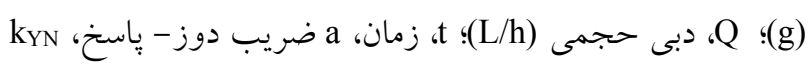
ثابت يون- نلسـون (1)

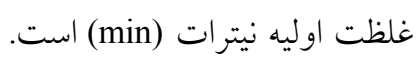

\section{نتايج و بحث}

شكله هاى او ب تصاوير SEM برك راش قبل و بعد از اصـلاح

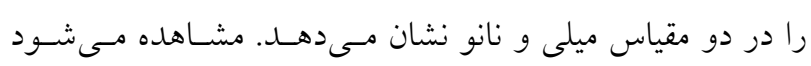



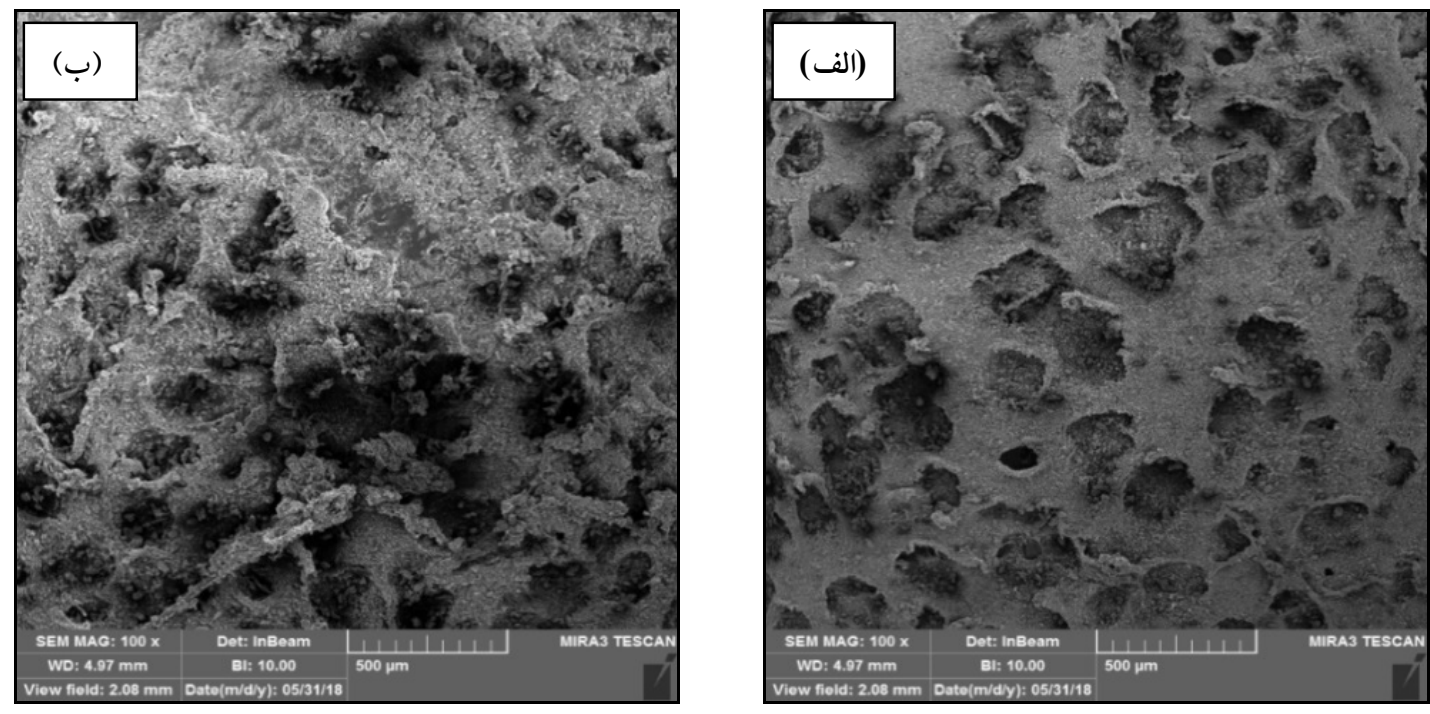

شكل r. تصاوير SEM نانوجاذب برى راش: الف) قبل از اصلاح و ب) بعد از اصلاح
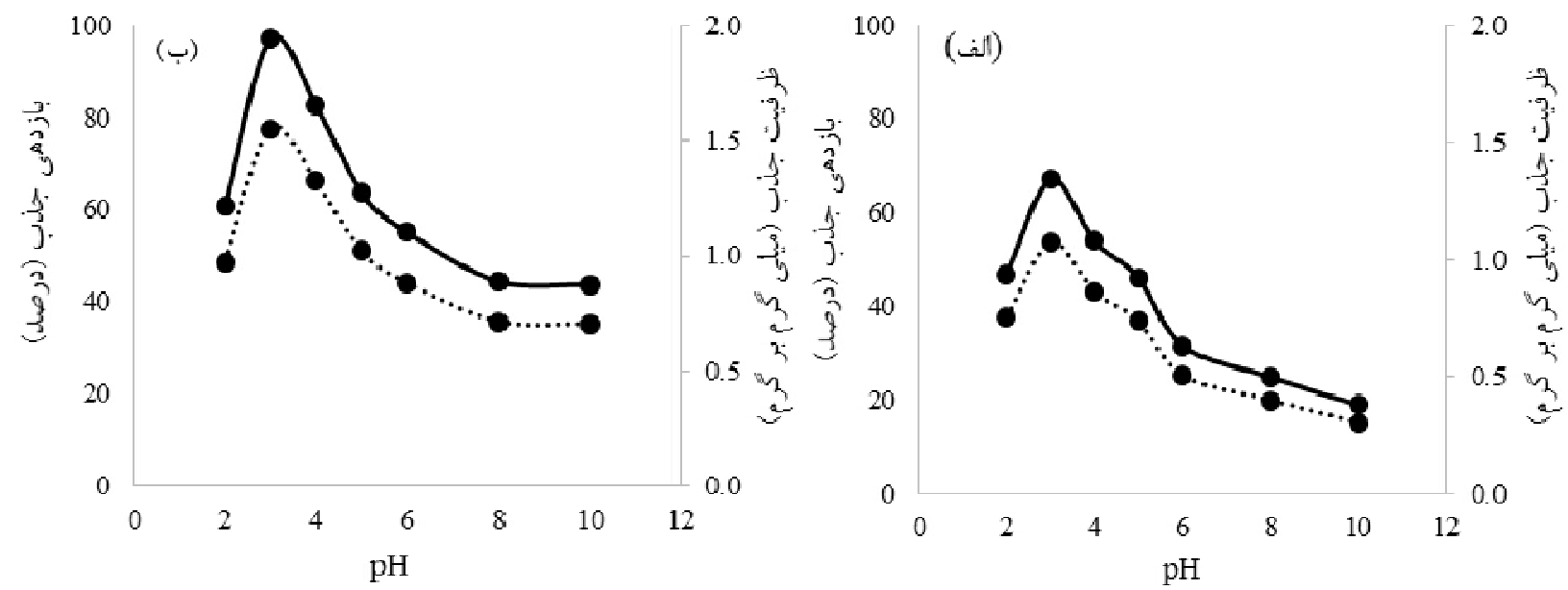

شكل r. تغييرات بازدهى و ظرفيت جذب نيترات با pH: الف) ميلى جاذب برى راش و ب) نانوجاذب برى راش

اثر زمان تماس بر جذب نيترات: نتايج تأثير زمان بر بازدهى و

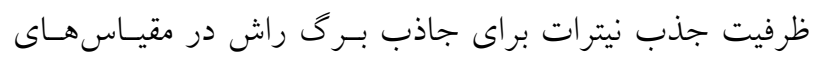

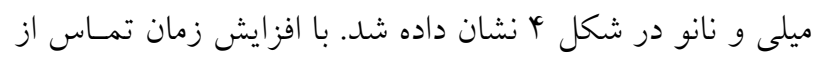

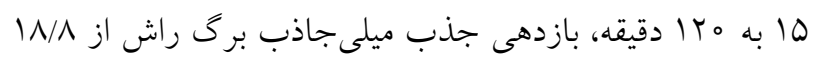

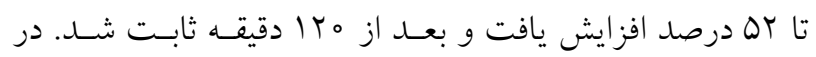

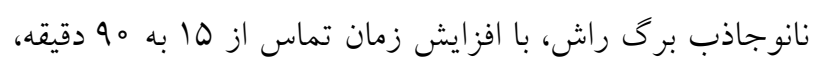

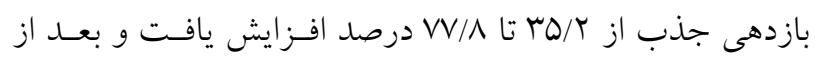
99 دقيقه تغيير محسوسى در ميزان جذب مشاهده نشد و مقدار

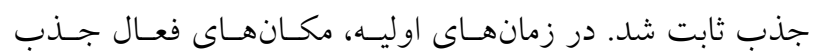

pH سطح جاذب بهتدريج كاهش يافته و رقابت بين يونهاى نيترات

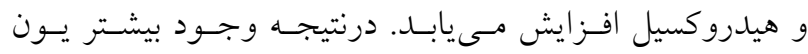

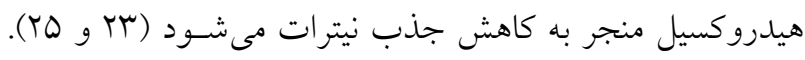

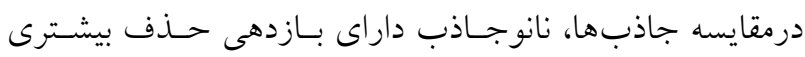

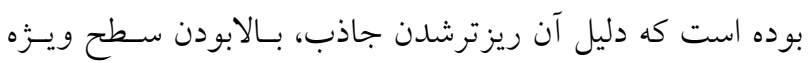

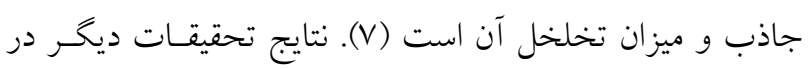
حذف نيترات، حداكثر جذب نيترات براى بعضى از جـاذبهـا در pH اسيدى اتفاق افتاد (9). 


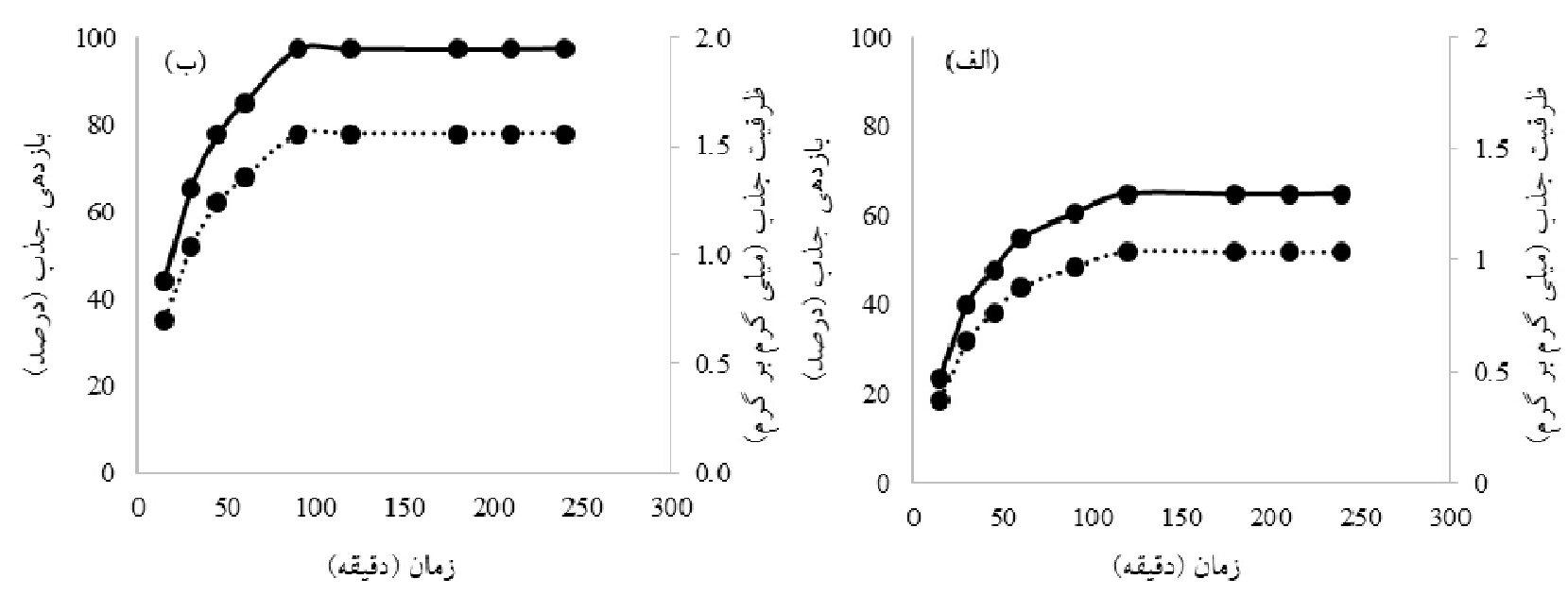

شكل f. تغييرات بازدهى و ظرفيت جذب نيترات با زمان: الف) ميلى جاذب برى راش و ب) نانوجاذب برى راش
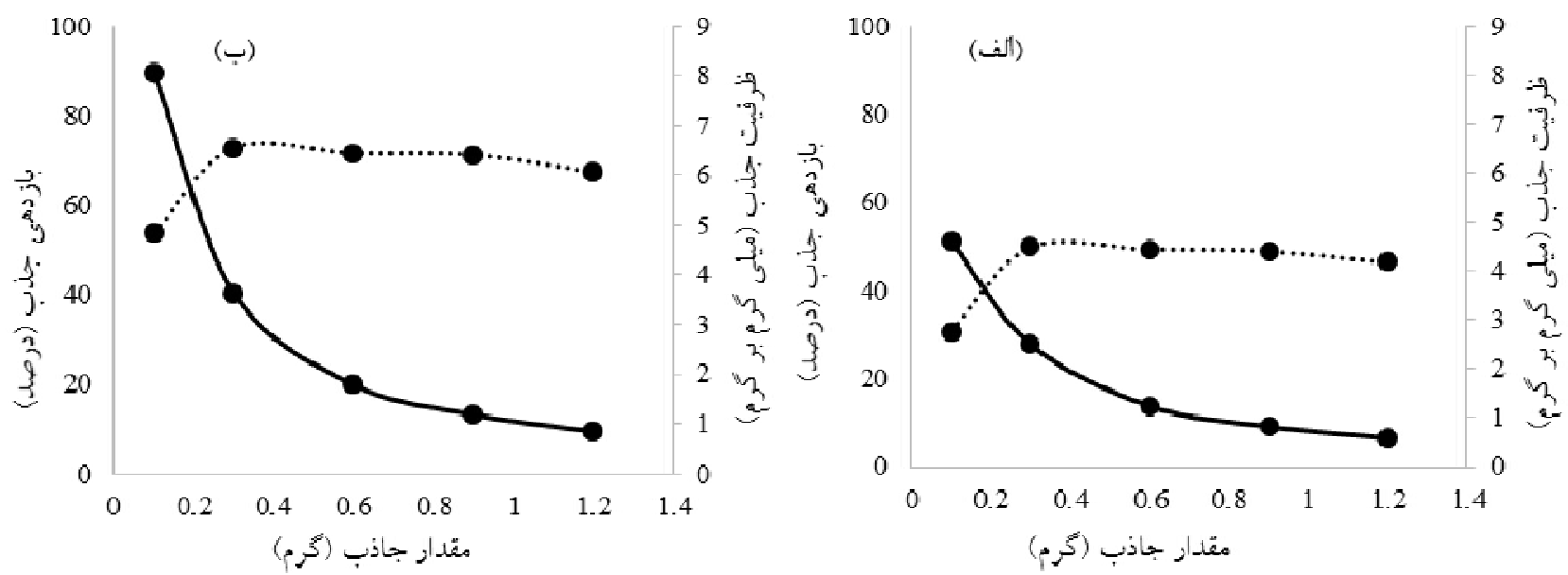

شكل ه. اثر مقدار جاذب بر بازدهى و ظرفيت جذب نيترات: الف) ميلى جاذب برى راش و ب) نانوجاذب برى راش

جذب نيترات در برابـر تغييـرات مقــدار جـاذب بـرى راش در مقياسهاى ميلى و نانو در شـكل ه نشـان داده شــه اسـت. بـا لـا

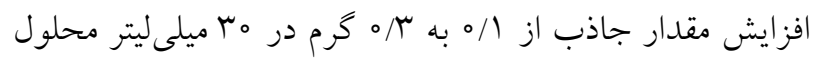

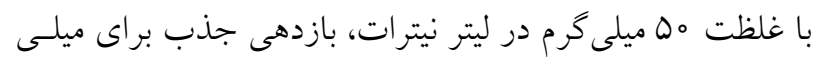

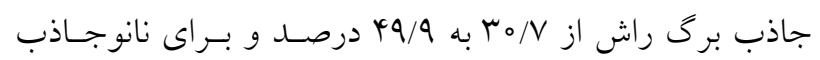

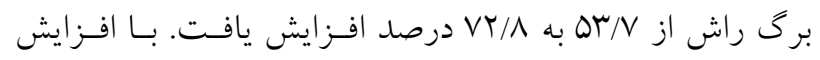

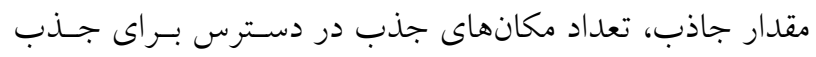

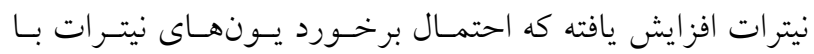
جاذب را افزايش داده، درنتيجه جذب بيشتر يـونهـاى نيتـرات

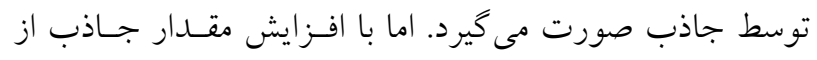

در سطح جاذب زياد بوده، درنتيجه فرصت و احتمـال برخهورد

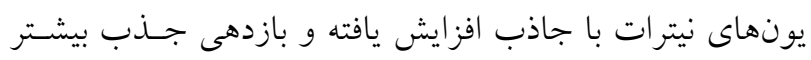

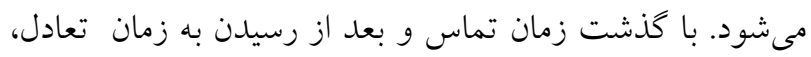
مكانهاى فعال در سطح جاذب توسط يونهاى نيتـرات اشـغال

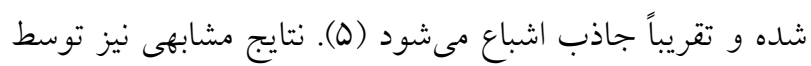

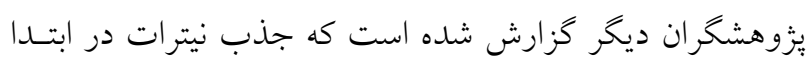

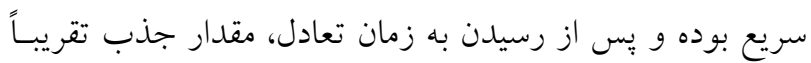
ثابت باقى ماند (19 و و برد). اثر جرم جاذب بر ميزان جذب: تغييـرات بـازدهى و ظرفيـت 


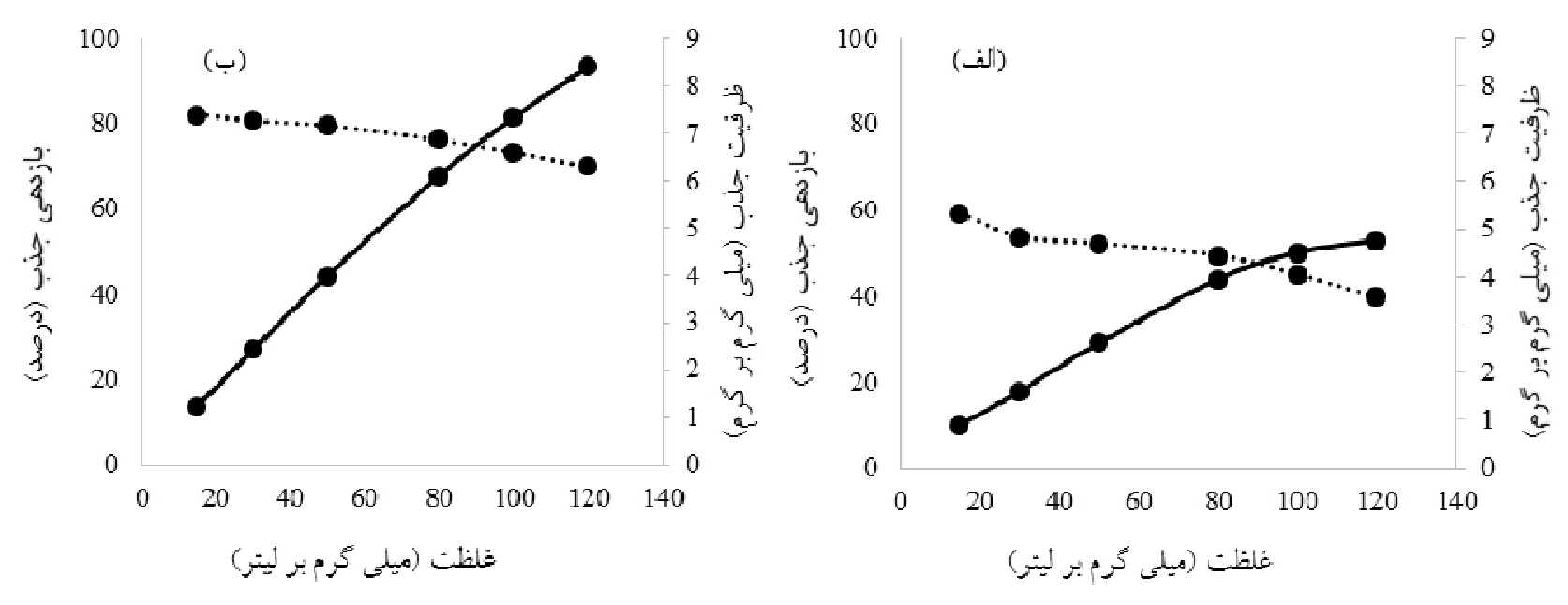

شكل צ. اثر غلظت اوليه بر بازدهى و ظرفيت جذب نيترات: الف) ميلى جاذب برى راش و ب) نانوجاذب برى راش

درنتيجه مكانهاى فعال جذب بيشترى براى يونها فراهم بـوده

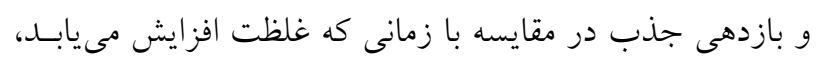

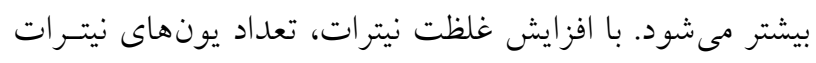

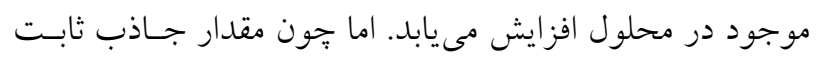

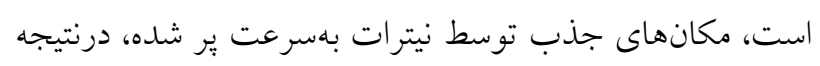

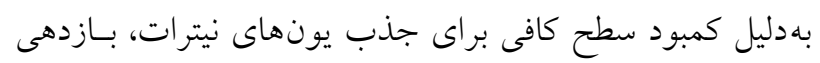

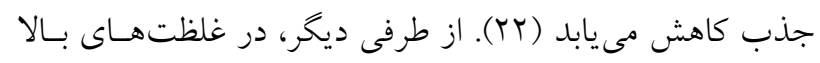
سرعت جذب بيشتر شده و ظرفيت جذب افزايش يافتـه اسـت.

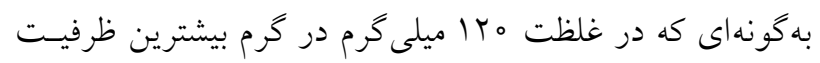

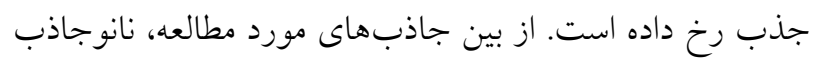

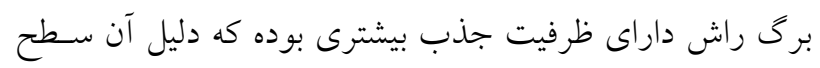

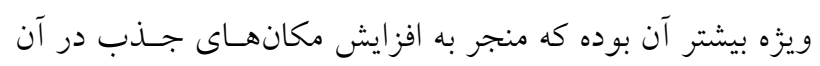

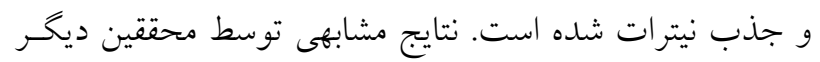

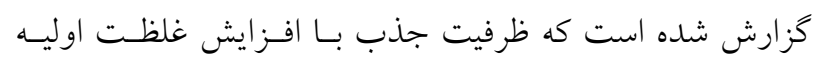

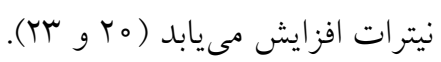

ايزوترم جذب: نتايج برازش مدلهــاى ايزوتـرم جـــب توسط

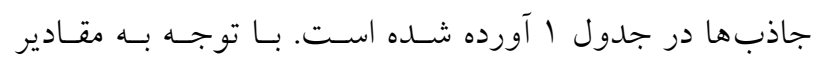

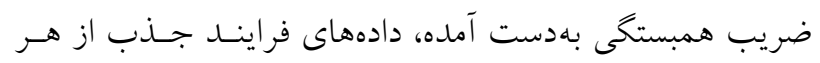

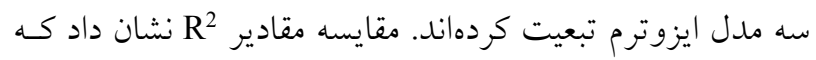

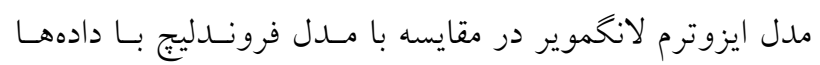

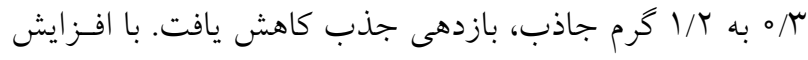

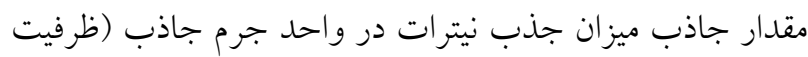

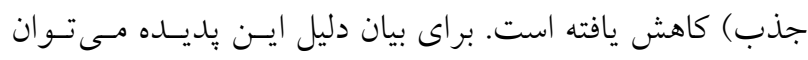

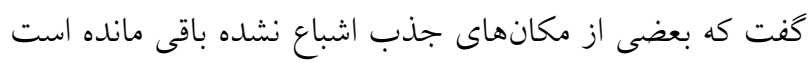
كه باعث كاهش ظرفيت جذب شده است (IV) (IV) بهعبارتى ديخر

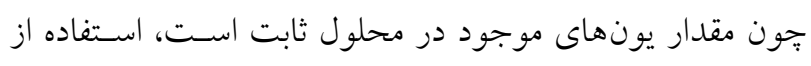

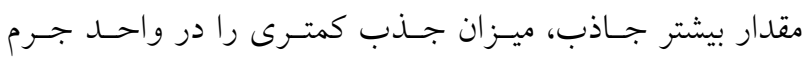

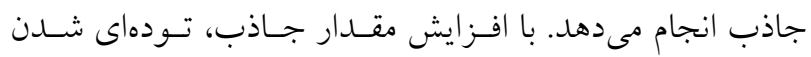
ذرات جاذب در مقادير زياد موجب كاهش سطح ويزه مى شــود. با افزايش مقدار جاذب از يك حد، روند غير اشباع ماندن مكسان

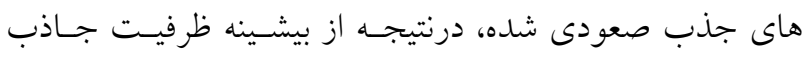

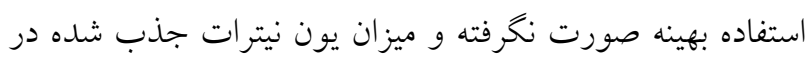
واحد جرم جاذب كاهش مى يابد (T9). اثر غلظت اوليه نيترات بر جذب: تغييرات بـازدهى و ظرفيـت

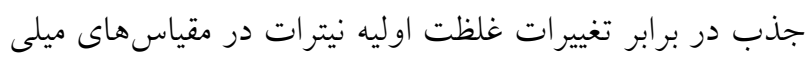

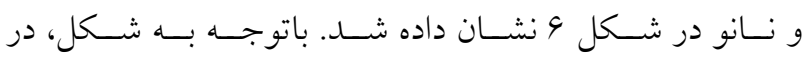

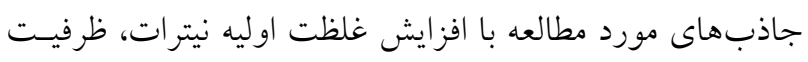

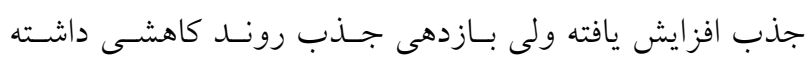

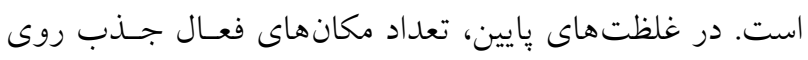
سطح جاذب در مقايسه با غلظتهاى بالاى نيترات، بيشتر است. 
جدول ا. بارامترهاى مدلهاى جذب ايزوترم برازش داده شده بر جذب نيترات توسط جاذب برگ راش

\begin{tabular}{|c|c|c|c|}
\hline نانو جادب برى راش & ميلى جاذب برى راش & يار امتر & مدل \\
\hline $.0 Y 99$ & .0194 & $\mathrm{~b}(\mathrm{~L} / \mathrm{mg})$ & \multirow{4}{*}{ لانخموير } \\
\hline $19 / 99$ & $\Lambda / r$ & $\mathrm{qm}(\mathrm{mg} / \mathrm{g})$ & \\
\hline $0 / 991$ &.$/ 990$ & $\mathrm{R}^{2}$ & \\
\hline.$/ 1110$ & $\circ / 1 \wedge$ & RMSE & \\
\hline o/gMGY & - TOYY & $\mathrm{KF}(\mathrm{L} / \mathrm{g})$ & \multirow{4}{*}{ فروندليج } \\
\hline $1 / \mu y$ & $1 / 791$ & $\mathrm{nF}$ & \\
\hline $0 / 919$ & $0 / 910$ & $\mathrm{R}^{2}$ & \\
\hline$\circ / 4 \circ V 1$ & OMIKT & RMSE & \\
\hline $0 / 4 V$ & - / Q9 & a (L/g) & \multirow{5}{*}{ ريدليج - يترسون } \\
\hline $0 / 014$ & $0 / 01$ & $\mathrm{~b}(\mathrm{~L} / \mathrm{g})$ & \\
\hline $1 / T \circ 4$ & $1 / 1 r q$ & $\mathrm{n}$ & \\
\hline $0 / 9991$ &.$/ 9190$ & $\mathrm{R}^{2}$ & \\
\hline ०/OYGY & $0 / 1491$ & RMSE & \\
\hline
\end{tabular}

با افزايش دبى جريان، زمان رسيدن به نقطـه اشـباع كمتـر شـده است. با افزايش دبى جريان ورودى، محلول با سرعت بيشـرى از بستر جاذب عبور مى كند. در مقابـل زمـانى كـه دبسى جريـان كمتر شده است، يونهاى نيترات فرصت بيشترى داشته تـا روى مكانهاى جذب قرار كيرند. درنتيجه زمان رخنـه طـولانى تـر و منحنى رخنه كشيدهتر شده اسـت (11). در مقـادير بـالاتر دبسى جريان، نيروهاى محــرى و نـرخ انتقـال جــرم افـزايش يافتـه و مقادير بيشترى از محلول روى ارتفاع مشخصى از بستر (منطقـه انتقال جرم) جذب شده و باعث سريعتر شدن اشباع شده اسـت (YY). زمان اشباع براى دبى جريانهاى ه، ^و ال إميلىليتـر در

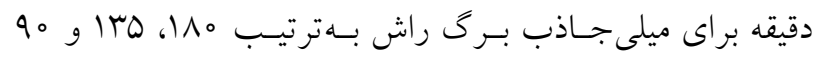

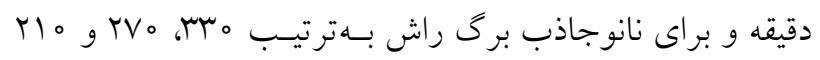
دقيقه، اتفاق افتاد. در يزّوهشهاى انجام شده ديخر نيز با افزايش دبى جريــان ورودى بـه سـتون، ظرفيـت جـــب كـاهش يافـت

$(r \circ, \mid \varphi)$

اثر تغييرات غلظت بر منحنى رخنه: تغييرات غلظـت بـا زمـان
همخوانى بيشترى داشته كه دلالت بر همخنى سطح جاذبهـاى مورد مطالعه است. بهعبارت ديخر جذب تكىلايهاى روى سـطح مكانهاى جذب همخن جاذب برى راش صورت گرفتسه اسـت (Y4). در مدل لانخموير qm نشاندهنده بيشـينه ظرفيـت جـــب نيترات است. مقايسه اين يارامتر نشان داد كـهـ بـــاى نانوجـاذب برى راش بيشينه ظرفيت جذب بيشتر از جاذب ديخر است كـه دليل آن كاهش اندازه ذرات، افزايش سطح ويثزه و واكنشيذيرى

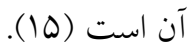
ضريب 1/n در مدل ايزوتـرم فرونــليج نشـاندهنـــه مطلوبيـتـ جذب است. اين ضريب بايد داراى مقاديرى بين صفر و ا باشد

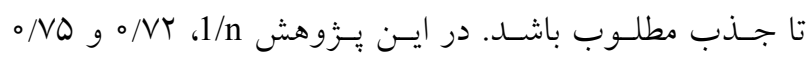
بهدست آملده است.

نتايج آزمايشهاى بيوسته اثر دبى جريان ورودى بر منحنى رخنسه: تغييـرات غلظـت بـا زمان بــراى جـاذب بـرى راش در مقيـاس ميلى و نـانو بـراى دبىهاى مختلف در شكل V نشان داده شد. ملاحظه مى شود كـه. 

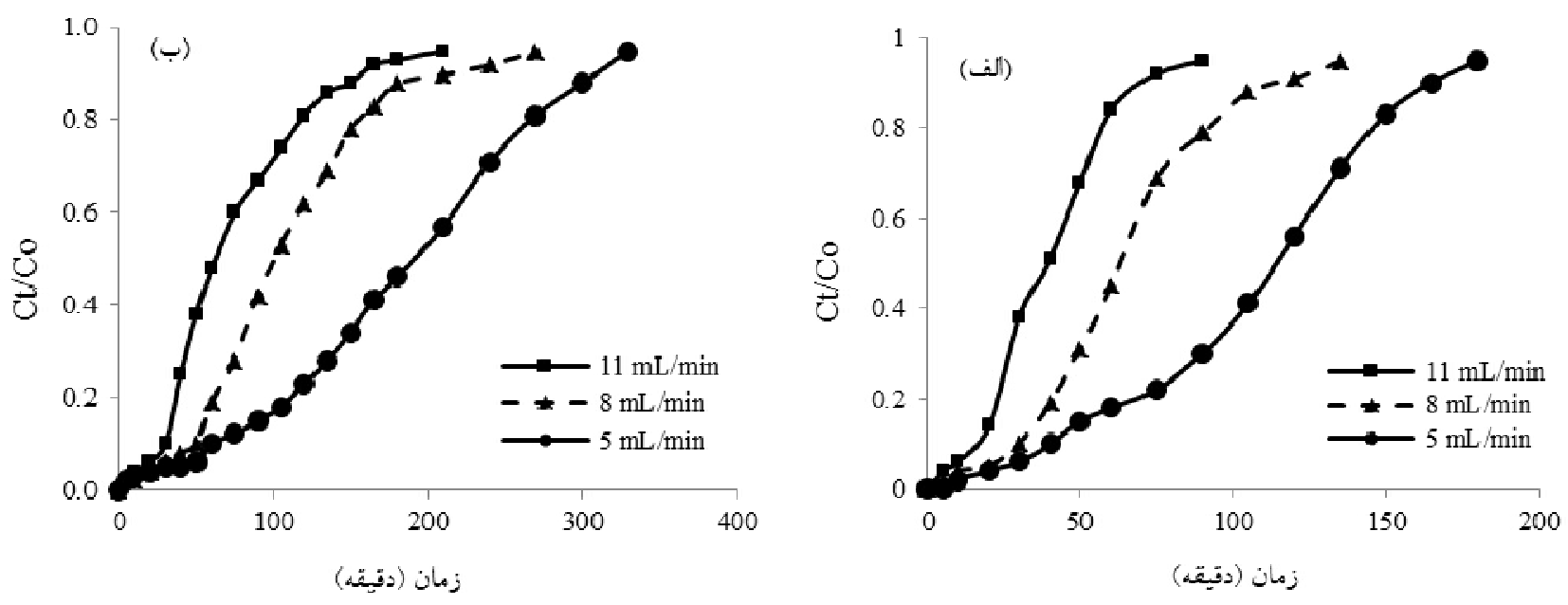

شكل V. منحنى رخنه در دبى هاى مختلف براى: الف) ميلى جاذب برى راش و ب) نانوجاذب برى راش
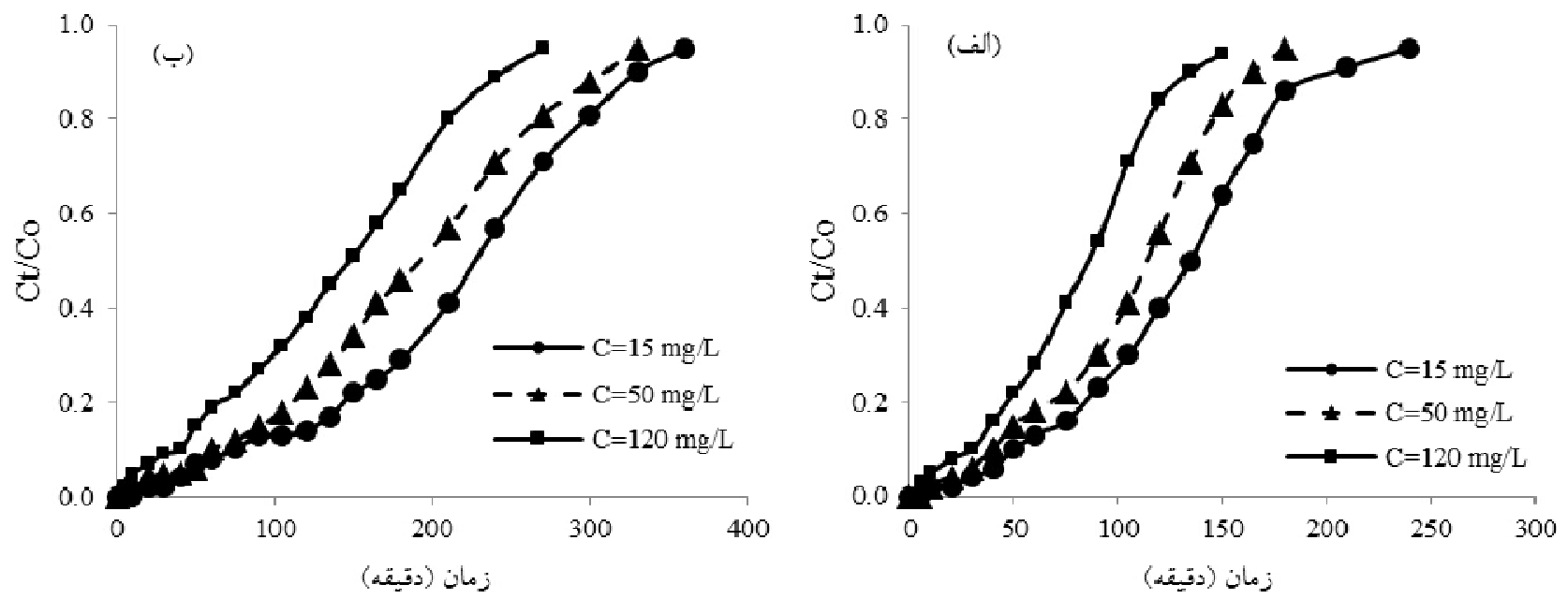

شكل ^. منحنى رخنه در غلظتهاى اوليه محلول مختلف براى: الف) ميلى جاذب برى راش و ب) نانوجاذب برى راش

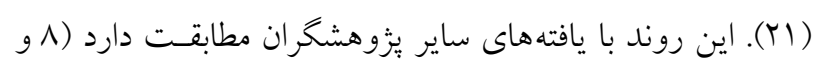

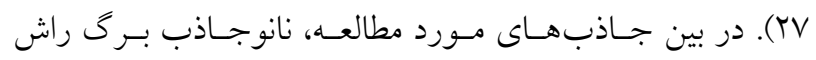

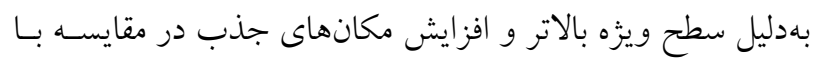
ميلى جاذب برى راش، داراى جذب بيشترى بوده است. همجنسين

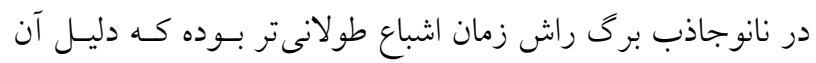

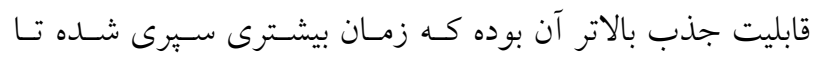
غلظت خروجى 90/ه غلظت ورودى نيترات شده است.

مدلسازى ستون جذب بيوسته مدلهاى توماس، دوز - بِاسخ و يون - نلسون بر نتايج حاصل از مدوله
براى جاذب برى راش در مقياس ميلى و نانو بــراى غلظـتهـاى

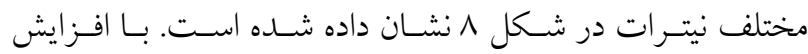

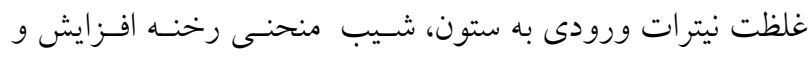

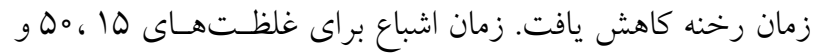

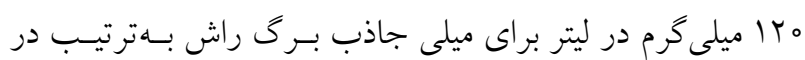

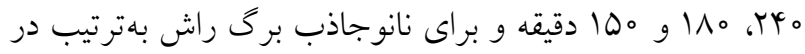

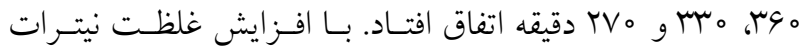
ورودى، مكانهاى جذب بيشترى توسط نيترات ير شــه و ميـزان

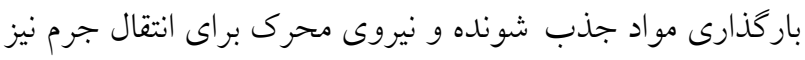

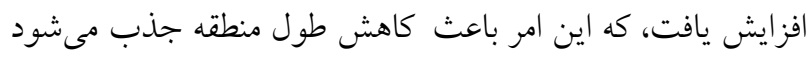


جدول r. مدلهاى جذب بيوسته برازش داده شده بر جذب نيترات توسط جاذب برى راش

\begin{tabular}{|c|c|c|c|c|c|c|c|c|c|c|}
\hline \multicolumn{3}{|c|}{ مدل يون- نلسون } & \multicolumn{3}{|c|}{ مدل دوز - ياسخ } & \multicolumn{3}{|c|}{ مدل توماس } & & \multirow{2}{*}{ جاذب } \\
\hline $\mathrm{R}^{2}$ & $\tau$ & $\mathrm{kYN}$ & $\mathrm{R}^{2}$ & qDR & a & $\mathrm{R}^{2}$ & qTh & $\mathrm{KTh}$ & & \\
\hline.$/ 994$ & $r q / 9$ & $0 / 0 \wedge \circ 4$ &.$/ 99 r$ & $1 / 199$ & $r / 990$ &.$/ 994$ & $1 / 991$ & .0990 & $\mathrm{Q}=11 \mathrm{~mL} / \mathrm{min}$ & \\
\hline.$/ 994$ & $94 / 0$ & $\circ / 0 \mathrm{VI}$ & $0 / 99 V$ & T/TOA & $r / \Delta T_{1}$ &.$/ 994$ & $r / T 49$ & $.09 \wedge \Delta$ & $\mathrm{Q}=\wedge \mathrm{mL} / \mathrm{min}$ & \\
\hline.$/ 994$ & $110 / 9$ & 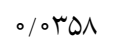 & $19 V 1$ & T/YYA & r/vAS &.$/ 994$ & T/OHA & $0 / 0$ pro & $\mathrm{Q}=\mathrm{Q} \mathrm{mL} / \mathrm{min}$ & ميلى جاذب \\
\hline $199 \mathrm{~V}$ & $|\pi| /$ & $\circ / \circ \mu_{\circ} \wedge$ &.$/ 914$ & $\circ / \Lambda V \mu$ & $r / \Lambda \circ \Lambda$ &.$/ 99 V$ & $\circ / 9 \circ r$ & וTMT & $\mathrm{C}=10 \mathrm{mg} / \mathrm{L}$ & برى راش \\
\hline.$/ 994$ & $110 / 9$ & loron &.$/ 9 V 1$ & T/KYA & r/vAS &.$/ 994$ & r/DrA & o/opro & $\mathrm{C}=\emptyset \circ \mathrm{mg} / \mathrm{L}$ & \\
\hline.$/ 991$ & $\Delta \mu / r$ & $0 / 04 t 5$ &.$/ 9 \vee 9$ & Y & $r / T / 9$ &.$/ 991$ & $\varphi / \Delta \Lambda$ & $0 / 0 Y \circ 4$ & $\mathrm{C}=1 r_{\circ} \mathrm{mg} / \mathrm{L}$ & \\
\hline.$/ 9 V^{4}$ & $V 1 / 0$ &.$\%$ rGV &.$/ 991$ & $r / 4 \vee q$ & $T / M V I$ & $/ 9 V 4$ & Y/VV & o/okto & $\mathrm{Q}=11 \mathrm{~mL} / \mathrm{min}$ & \\
\hline 1991 & $109 / 9$ & ०० ए। &.$/ 991$ & T/AYG & $r / 911$ &.$/ 991$ & $r / 01 r$ & \% & $\mathrm{Q}=\wedge \mathrm{mL} / \mathrm{min}$ & \\
\hline.$/ 991$ & $1 M M / \Lambda$ & 10111 & ./91r & $r / 191$ & $r / \circ \Lambda$ &.$/ 991$ & T/MTY & \%OYIV & $\mathrm{Q}=\emptyset \mathrm{mL} / \mathrm{min}$ & نانوجاذب برى \\
\hline $.0 / 990$ & TYT/G & $0 / 0110$ & /9VF & 1/1/1 & r/vGQ &.$/ 990$ & I/IVG & $\% / 019$ & $\mathrm{C}=10 \mathrm{mg} / \mathrm{L}$ & راش \\
\hline.$/ 991$ & $1 M M / \Lambda$ & $0 / 01 \wedge 1$ & ./9Ar & $r / 191$ & $r / \circ \Lambda \Lambda$ &.$/ 991$ & T/MTY & \% TIV & $\mathrm{C}=\emptyset \circ \mathrm{mg} / \mathrm{L}$ & \\
\hline.$/ 994$ & $\mid k+/ 0$ & $0 / 0 Y_{01}$ & $0 / 994$ & $\Delta / V \circ r$ & $r / Y \Delta T$ &.$/ 994$ & $9 / 1 \circ 0$ & $0 / 0101$ & $\mathrm{C}=1 \mathrm{r} \circ \mathrm{mg} / \mathrm{L}$ & \\
\hline
\end{tabular}

جذب بيشتر شد، ولى بازدهى حذف كاهش يافت. مــلهـاى

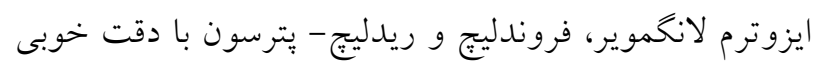

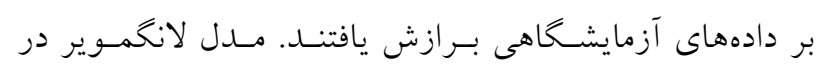

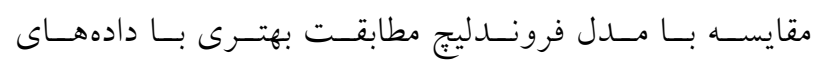

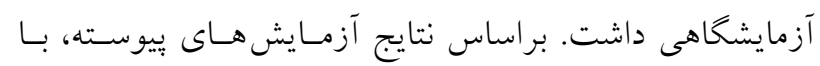
افزايش دبى جريان ورودى به ستون از ه به اله ميلسىليتـر در دقيقه زمان اشباع براى ميلى جـاذب بـرى راش از م11 بـــ

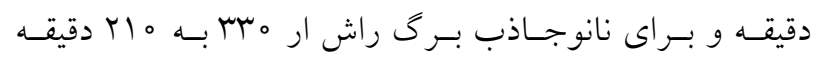

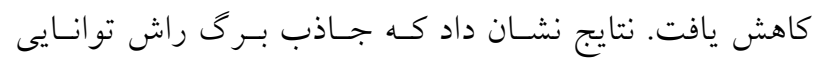
جذب نيترات از محلول آبى را دارا است. با توجه به فراوانى درخت راش در استانهاى شمالى، مى تواند بـهـعنـوان جـاذب

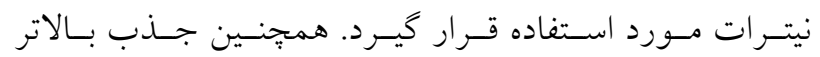
نانوجاذب مورد مطالعه نشاندهنده توانمندى فنـاورى نـانو در حذف آلايندهها است.

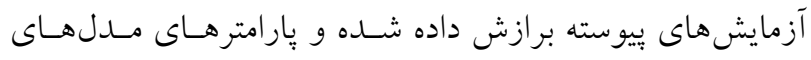
جذب بيوسته نيترات در دبىها و غلظت هاى مختلف در جدول r آورده شده است. با توجه به جدول rا، با كاهش دبى جريان و افزايش غلظت نيترات ورودى به ستون ظرفيت جـــب، ؛ــارمتر qTh در غلظـتهــاى اوليـه بيشـتر، مكــانهـاى جــــب در دسـترس محدودتر شده درنتيجه سرعت جذب يـا همـان ثابـت سـرعت توماس كمتر شده است (Y). در مدل يون- نلسـون، بـا افـزايش دبى جريان ورودى ثابت KYN افزايش و ح، بهدليل كاهش زمـان تماس، كاهش يافته است.

\section{نتيجه گيرى كلى}

در آزمايش هاى نابيوسته، pH و جرم بهينه براى حذف نيترات ץ و ץ/ه گرم بهدست آمد. زمان تعادل براى ميلى و نانوجاذب برى راش به ترتيب ه rا و هو دقيقه بهدست آمد و بعــ از آن مقدار جذب تقريباً ثابت شد. با افزايش غلظت نيترات، ظرفيت 
1. Abedi-Koupai, J., F. Mousavi and A. Motamedi. 2010. Effect of clinoptilolite zeolite application on reducing urea leaching from soil. Journal of Water and Wastewater 21(3): 51-57. (In Farsi).

2. Aksu, Z. and F. Gonen. 2004. Biosorption of phenol by immobilized activated sludge in a continuous packed bed: prediction of breakthrough curves. Process Biochemistry 39: 599-613.

3. Baboli, N. and A. Bafkar. 2019. Investigation of nitrate element removal by nanostructure adsorbents in continuous adsorption system. Journal of Environmental Sciences Studies 4(2): 1340-1349. (In Farsi)

4. Bhatnagara, A., E. Kumarb and M. Sillanpääc. 2010. Nitrate removal from water by nano-alumina: Characterization and sorption studies. Chemical Engineering Journal 163(3): 317-323.

5. Bozorgpour, F., H. F. Ramandi, P. Jafari, S. Samadi, S. S. Yazd and M. Aliabadi. 2016. Removal of nitrate and phosphate using chitosan $/ \mathrm{Al}_{2} \mathrm{O}_{3} / \mathrm{Fe}_{3} \mathrm{O}_{4}$ composite nanofibrous adsorbent: Comparison with chitosan/ $/ \mathrm{Al}_{2} \mathrm{O}_{3} / \mathrm{Fe}_{3} \mathrm{O}_{4}$ beads. International Journal of Biological Macromolecules 93: 557-565.

6. Fan, C. and Y. Zhang. 2018. Adsorption isotherms kinetics and thermodynamics of nitrate and phosphate in binary systems on a novel adsorbent derived from corn stalks. Journal of Geochemical Exploration 188: 95-100.

7. Farasat, M., S. Boroomandnasab, J. Abedi Koupai, N. Jafarzadeh, H. Moazed and M. Saiedian. 2012. Nitrate contaminated water treatment using micro and nanostructured sugarcane straw. Journal of Science and Technology of Agriculture and Natural Resources, Water and Soil Science 16(61): 83-95. (In Farsi).

8. Gouran-Orimi, R., B. Mirzayi, A. Nematollahzadeh and A. Tardast. 2018. Competitive adsorption of nitrate in fixed-bed column packedwith bio-inspired polydopamine coated zeolite. Journal of Environmental Chemical Engineering 6: 2232-2240.

9. Hu, Q., N. Chen, C. Feng, W. Hu, J. Zhang, H. Liu and Q. He. 2016. Nitrate removal from aqueous solution using granular chitosan-Fe(III)-Al(III) complex: Kinetic, isotherm and regeneration studies. Journal of the Taiwan Institute of Chemical Engineers 63: 216-225.

10. Kaewprasit, C., E. Hequet, N. Abidi and J. Gourlot. 1998. Application of methylene blue adsorption to cotton fiber specific surface area measurement: Part I Methodology. Journal of Cotton Science 2(4): 164-173.

11. Kang, J. -K., S. -C. Lee and S. -B. Kim. 2019. Synthesis of quaternary ammonium-functionalized silica gel through grafting of dimethyl dodecyl [3-(trimethoxysilyl) propyl] ammonium chloride for nitrate removal in batch and column studies. Journal of the Taiwan Institute of Chemical Engineers 102: 153-162.

12. Keeney, D. R. and D. W. Nelson. 1982. N-inorganic forms Methods of Soil Analysis. Part 2. All Page. Miller, R. H. and D. R. Keeney, (Eds.). Agronomy 9: 643-698.

13. Keranen, A., T. Leiviska, O. Hoemi and J. Tanskanen. 2015. Removal of nitrate by modified pine sawdust: Effects of temperature and co-existing anions. Journal of Environmental Management 147: 46-54.

14. Kizito, S., S. Wu, S. M. Wandera, L. Guo and R. Dong. 2016. Evaluation of ammonium adsorption in biochar-fixed beds for treatment of anaerobically digested swine slurry: Experimental optimization and modeling. Science of the Total Environment 563: 1095-1104.

15. Malekian, R., J. Abedi-Koupai, S. Eslamian, F. Mousavi, K. Abbaspour and M. Afyuni. 2011. Ion-exchange process for ammonium removal and release using natural Iranian zeolite. Applied Clay Science 51: 323-329.

16. Mazarji, M., B. Aminzadeh, M. Baghdadi and A. Bhatnagar. 2017. Removal of nitrate from aqueous solution using modified granular activated carbon. Journal of Molecular Liquids 233: 139-148.

17. Moazami, H. 2009. Effect of natural adsorbents on copper removal from polluted waters. Master thesis, Tarbiat Modares University, Tehran, I.R. Iran. (In Farsi).

18. Mohammadi, E., H. Daraei, R. Ghanbari, S. D. Athar, Y. Zandsalimi, A. Ziaee and K. Yetilmezsoy. 2019. Synthesis of carboxylated chitosan modified with ferromagnetic nanoparticles for adsorptive removal of fluoride, nitrate, and phosphate anions from aqueous solutions. Journal of Molecular Liquids 273: 116-124.

19. Mondal, N. K., P. Ghosh, K. Sen, A. Mondal and P. Debnath. 2019. Efficacy of onion peels towards removal of nitrate from aqueous solution and field samples. Environmental Nanotechnology Monitoring and Management 11: 100222.

20. Olgun, A., N. Atar and S. Wang. 2013. Batch and column studies of phosphate and nitrate adsorption on waste solids containing boron impurity. Journal of Chemistry Engineering 222: 108-119.

21. Padmesh, T. V. N., K. Vijayaaraghavan, G. Sekaran and M. Velan. 2005. Batch and column studies on biosorption of acid dyes on fresh water macro agga Azalla filiculoids. Journal of Hazard Materials 125: 121-129.

22. Qiao, H., L. Mei, G. Chen, H. Liu, Ch. Peng, F. Ke, R. Hou, X. Wan and H. Cai. 2019. Adsorption of nitrate and phosphate from aqueous solution using amine cross-linked tea wastes. Applied Surface Science 483: 114-122.

23. Rashidi Nodeh, H., H. Sereshti, E. Zamiri Afsharian and N. Nouri. 2017. Enhanced removal of phosphate and nitrate ions from aqueous media using nanosized lanthanum hydrous doped on magnetic graphene nanocomposite. Journal of Environmental Management 197: 265-274. 
24. Singh, S., V. C. Srivastava and I. D. Mall. 2009. Fixed-bed study for adsorptive removal of furfural by activated carbon. Colloids and Surfaces A: Physicochemical Engineering Aspects 332: 50-56.

25. Song, W., B. Gao, X. Xu, F. Wang, N. Xue, S. Sun and R. Jia. 2016. Adsorption of nitrate from aqueous solution by magnetic amine-crosslinked biopolymer based corn stalk and its chemical regeneration property. Journal of Hazardous Materials 304: 280-290.

26. Viglašová, E., M. Galamboš, Z. Danková, L. Krivosudsky', C. L. Lengauer, R. Hood-Nowotny, G. Soja, A. Rompel, M. Matík and J. Briancin. 2018. Production characterization and adsorption studies of bamboo-based biochar/montmorillonite composite for nitrate removal. Waste Management 79: 385-394.

27. Wu, Y., Y. Wang, J. Wang, S. Xu, L. Yu, C. Philippe and T. Wintgens. 2016. Nitrate removal from water by new polymeric adsorbent modified with amino and quaternary ammonium groups: Batch and column adsorption study. Journal of the Taiwan Institute of Chemical Engineers 1-9.

28. Xing, X., B. Gao, Q. Q. Zhong, B. Yue and Q. Zhong. 2010. Preparation of agricultural by product based anion exchanger and its utilization for nitrate and phosphate removal. Bioresource Technology 101: 8558-8564.

29. Yadava, A. K., R. Abbassia, A. Guptac and A. Dadashzad. 2013. Removal of fluoride from aqueous solution and groundwater by wheat straw sawdust and activated bagasse carbon of sugarcane. Ecological Engineering 52: 211218. 


\title{
Use of Modified Nano Particles of Beech Leaves for Nitrate Removal from Aqueous Solutions in the Column System
}

\author{
T. Dehghan ${ }^{1}$, M. A. Gholami Sefidkouhi ${ }^{1 *}$, M. Khoshravesh ${ }^{1}$ and N. Samadani \\ Langroudi ${ }^{2}$
}

(Received: November 30-2019; Accepted: September 9-2020)

\begin{abstract}
In this research, the nitrate removal by beech leaves was investigated in batch and column systems. The batch experiment was performed to address the effect of $\mathrm{pH}$, contact time, adsorbent dosage and initial nitrate ion concentration on the nitrate removal. The results showed that with an increase in $\mathrm{pH}$, the removal efficiency and adsorption capacity were decreased and nitrate removal by millimeter and nano adsorbent beech leaves reached equilibrium 120 and 90 minutes after experiment, respectively. With an increase in the nitrate concentration, the removal efficiency was decreased from $59.2 \%$ to $39.7 \%$ and $82.1 \%$ to $69.9 \%$ for millimeter and the nanoparticles of Beech leaves, respectively. In fixed-bed column adsorption experiments, the flow rates of 5, 8 and $11 \mathrm{ml} / \mathrm{min}$ and the nitrate concentration of 15,50 and $120 \mathrm{mg} / \mathrm{L}$ were studied. The results showed with an increase in the nitrate concentration from 15 to $120 \mathrm{mg} / \mathrm{L}$, the saturation time was decreased from 240 to 150 and 360 to 270 minutes for millimeter and nanoparticles of Beech leaves, respectively. Thomas, Dose-response and Yoon-Nelson models were fitted to the results of the continuous experiments. The Thomas model fitted the experimental data with high accuracy. Compared to the adsorbents, nano-adsorbent had more adsorption capacity in the batch and column systems.
\end{abstract}

Keywords: Batch experiment, Beech Leaf, Fixed-Bed Column, Nano adsorbent.

1. Water Engineering Department, Sari Agricultural Sciences and Natural Resources University, Sari, Iran.

2. Chemistry Department, Golestan University, Gorgan, Iran.

Corresponding author, Email: ma.gholami@sanru.ac.ir 